\title{
The Quality of Play Center Activities of Early Childhood Education in China
}

\author{
Xiaolin Liu ${ }^{1,3}$, Biying $\mathrm{Hu}^{2} \&$ Jian-hao Huang ${ }^{1}$ \\ ${ }^{1}$ China-ASEAN International College, Druakij Pudit University, Bangkok, Thailand \\ ${ }^{2}$ Faculty of Education, University of Macau, Macau, China \\ ${ }^{3}$ School of Early Childhood Education, Shandong Yingcai University, Jinan, China \\ Correspondence: Jian-hao Huang, China-ASEAN International College, Druakij Pudit University, Bangkok, \\ Thailand.
}

Received: May 13, 2019 Accepted: July 19, 2019 Online Published: July 21, 2019

doi: 10.5539/elt.v12n8p95 URL: https://doi.org/10.5539/elt.v12n8p95

\begin{abstract}
As one typical form of play, play center activities are commonly used in early childhood education programs in China. This study used the Activities Sub-scale of the Chinese Early Childhood Environment Rating Scale (CECERS) to measure the quality of the play center activities in K2 (4-5 years old) classroom, which based on a stratified random selection of 48 classrooms in Guangdong Province in China. Results found that the overall quality of play center activities was slightly below qualified (5 points), and there are significant differences between urban and rural, private and public, high and low level of kindergartens. Quality of three dimensions (material and space, opportunity and time, design and organization) also showed a medium level (above 4 points), and significant differences of three dimensions are found between urban and rural, private and public, high and low level of kindergartens. Findings and implications will help teachers to better support and enhance children's play center activities and early learning.
\end{abstract}

Keywords: quality of play center activities, early childhood education, China

\section{Introduction}

\subsection{Play Center Activities in China}

Early childhood education institutions, usually called "kindergarten" or "you er yuan" in China, are the most prevalent form of early childhood education institutions serving children aged three to six. Early childhood education experience provides children daily nursing, learning and play environment and opportunities. Play is an essential vehicle for children developing self-regulation, promoting language, cognitive, and social skills (Copple \& Bredekamp, 2009). It is a common assumption that play is the basic activity in early childhood education, and play center activities are considered as a prevalent form of play in kindergartens (Duncan \& Tarulli, 2003; Zigler, Singer, \& Bishop, 2004; Catron \& Allen, 2007; Hirsh-Pasek, Golinkoff, Berk, \& Singer, 2009).

Play center activities are also called guided play, or learning center activities in western countries, and it is called corner play or interest area activities in China. In kindergarten, according to the needs of children and the teaching goal, some well-organized learning centers (i.e., fine motor, art, music, blocks, sand/water, dramatic play, science, math) full of stimulating materials and well-planned activities are set up in the classroom and corridor. In this childcare environment, children usually get a rich experience and a free atmosphere according to their wishes and initiative choices. Play center activities, which emphasize the role and value of learning in supporting an educational environment, accepted by early childhood program practice in the past few decades (Davidson, 1998; Elias \& Berk, 2002; Johnson, Christie, \& Wardle, 2005; Hirsh-Pasek et al., 2009; Zigler \& Bishop-Josef, 2009). As is emphasized "play is the basic activity in preschool education" in the political contexts by the Ministry of Education of China (2001), these child-led play activities are commonly used in the kindergartens in China from urban to rural areas. Kindergarten teachers have fostered the sense of this kind of play and endorsed this child-initiated play as the practical curricular approach, which is the same in China (Zhu, 2007; Xu \& Zhao, 2014; Huang, 2014; Hu, Fan, Sao Leng Ieong, \& Li, 2015). 


\subsection{Key Components of Play Center Activities}

Appropriate design and proper setting are the premises of play center activities. As Good and Nedler (1974) revealed, play should provide positive emotional atmosphere, fruitful materials, and equipment, and reduce restrictions on children to help children develop their skills and gain different and meaningful experience freely. What are the critical components of high quality play center activities? The idea of high quality of play which includes more extended play periods, lots of realistic props and open materials can be used to better understand play center activities (Copple \& Bredekamp, 2009). Based on the existing literature and practice in kindergartens, this study proposed three key components as foundations of play center activities.

\subsubsection{Sufficient Space and Materials}

Sufficient space and materials are crucial elements in play center activities. They facilitate classroom management and support the implementation of curricular goals and objectives (Catron \& Allen, 2007). Sufficient space requires room for numbers of children to freely operation, without being restricted by the size and crowded conditions (Cryer, Harms, \& Riley, 2003). Besides, proper play center environments in the classroom show clear boundaries between areas with adequate space and avoiding interference between activities. There should be enough pieces of equipment and space accessible to a number of children, and they are also should be a variety of interesting options for chosen (Duncan \& Tarulli, 2003). A wide range of materials should be provided, including those familiar, novel, natural, and open materials in order to support exploration in the play.

\subsubsection{Adequate Time and Opportunity Provided}

In general, it is necessary to provide ample space, a variety of materials and activities, and encourage children to move freely without being limited to a small area (Holt, 2010). However, Chudacoff (2007) found that children`s free play with peers has declined sharply over the past half-century in western countries. Play deprivation has adverse physical and psychological consequences of children, so researchers advocate that children should be given adequate time and opportunities of play every day (Panksepp, 2007; Fisher, Hirsh-Pasek, Golinkoff, Singer, \& Berk, 2011). Although traditional group-teaching and other daily activities take up most of the time in kindergarten, children should have specific time and opportunities to play freely in play centers according to the schedule. In these play centers, children can freely choose the area, independently operate the material and determine the speed and difficulty of materials at the level of children`s abilities (Sylva et al., 2007). Teachers should lead to well-prepared and organized activities to ensure that high-level activities are taken place to provide the full free time of free play for children.

\subsubsection{Responsive Interactions From Teachers}

All researchers agree on the role of teachers in play center activities. They believe that teachers can improve, enrich, and extend children's play through using effective strategies of suggesting, participating, and redirecting (Schweinhart, 1988; Barnett, 2003; Epstein, 2014; Johnson et al., 2005; Hu, Dieker, Yang Y., \& Yang N., 2016; $\mathrm{Hu}$ et al., 2017). Effective teacher participation in children`s play means sensitive attention to children`s interests and development needs, selective choice of when to get involved, expression of appreciation and respect for children`s perspectives, and recognition of children`s efforts and abilities. On the other hand, if teachers provide too much control, constraints, or interrupts, it usually damages the play. The teacher's role is responsible for providing children with a variety of activity materials, implementation, and positive guidance.

\subsection{Current Research of Play Center Activities in China}

At present, relevant researches in China mainly focus on the description of the current situation in kindergartens. The descriptive research on play center activities in China mainly focuses on time, setting, teachers' guidance, and other aspects. It was shown that existing problems of play center activities including lack of time for free play center activities; a variety of materials but with incomplete autonomy of children. The role of teachers is ambiguous and aimless, mainly to ensure that the activities can be carried out (Han, 2013; Li et al., 2014; Gu, 2016; Chen \& Li, 2015).

In recent years, the research on play center activities has been further deepened, and scientific measurement is considered to evaluate the quality of play center activities, such as the Early Childhood Environment Rating Scale-Revised (ECERS-R) accepted in many countries (Gol-Guven, 2009). In China, few researchers have tried to measure the quality of early childhood education by ECERS-R. In order to reflect Chinese social and cultural contexts, $\mathrm{Li}$ and $\mathrm{Hu}$ (2012) modified CECERS based on a rigorous adaptation of ECERS-R ( $\mathrm{Li} \& \mathrm{Hu}, 2012$ ). Chen and $\mathrm{Li}$ (2015) used CECERS to measure the quality of play center activities in 88 kindergartens in Zhejiang Province. The results showed that the overall quality of play center activities in Zhejiang is not high; 
play center activities had a significant weak predictive effect on children's development results. Luo (2014) also used the CECERS in one city and found that the quality of the play center activities, especially the materials and opportunities offered need to be improved.

In summary, studies found that there are some problems with play center activities, and the practice needs to be improved (Yang, 2011; Yang \& Deng, 2012; Xu \& Zhao, 2014; Chen \& Li, 2015). However, there are few empirical studies on the quality of play center activities by using effective measurement tools such as CECERS in China (Luo, 2014; Chen \& Li, 2015). The purpose of this study is to explore the current situation of play center activities in other regions in China by using CECERS, and present the detailed quality of play center activities (including space and materials, time and opportunity, design and organization). The results are expected to let the kindergarten teachers know how to carry out and better support play center activities and early learning for children.

\section{Method}

\subsection{Participants}

This study took place in Guangdong Province with a population of more than 100 million, which has a more developed economy in China. In 2017, the gross enrollment rate of preschool education in Guangdong reached $109.08 \%$, and standardized kindergartens accounted for $74.57 \%$. The number of kindergarten children per million people ranks first, accounts for $9.6 \%$ in China (Guangdong Provincial Department of Education, 2018). The study used a stratified random sampling approach to select participants from three regions selected based on per capita GDP to represent high, middle, and low socioeconomic development of Guangdong. A random sample of 9-20 kindergartens within each region was selected from a complete list provided by the local education department, and one K2 (4-5 years old) classroom was randomly selected in each sample kindergarten, totally 48 classrooms (Table 1 ).

The sample included 16 urban and 32 rural classrooms. $45.8 \%$ of the kindergartens are at first-class at the provincial and municipal level, while $54.2 \%$ are at the standardized and unrated level. Classroom size ranged from 17 to 56 students (Mean $=36, \mathrm{SD}=7.32$ ), and classroom child-teacher ratio was 6 to 39.5 (Mean $=16, \mathrm{SD}$ =6) (Table 2).

Table 1. Descriptive statistics of the kindergarten background information

\begin{tabular}{llll}
\hline Variable & & $N$ & Percentage (\%) \\
\hline Region & Zhongshan & 20 & 41.7 \\
& Zhaoqing & 19 & 39.6 \\
\multirow{3}{*}{ Location } & Guangzhou & 9 & 18.8 \\
& Urban & 16 & 33.3 \\
\multirow{2}{*}{ Funding Source } & Rural & 32 & 66.7 \\
& Private & 36 & 25 \\
Level & Public & 12 & 75 \\
& First-class at provincial & 22 & 45.8 \\
& and municipal level & & \\
& Standardized and unrated & 26 & 54.2 \\
\hline
\end{tabular}

Table 2. Descriptive statistics of the classroom background information

\begin{tabular}{llllll}
\hline Variable & $N$ & $M$ & $S D$ & Min & Max \\
\hline Classroom size & 48 & 36.00 & 7.32 & 16.00 & 56.00 \\
Child-teacher ratio & 48 & 16.21 & 6.00 & 6.00 & 39.50 \\
\hline
\end{tabular}

\subsection{Measurement}

Chinese Early Childhood Environment Rating Scale (CECERS; Li \& Hu, 2012) is the instrument to measure the 
quality of early childhood education in Chinese social and cultural contexts. The CECERS comprises 51 items organized in eight sub-scales, and the sub-scale of Activities includes 9 items: (1) role/drama (3 items), (2) blocks (3 items), (3) fine motor (3 items), (4) language (4 items), (5) mathematics (3 items), (6) nature/science (3 items), (7) music/rhythm (3 items), (8) art (3 items), and (9)sand/water (3 items), mainly evaluating the preparedness and implementation of play center activities. CECERS uses a 9-point scoring system ranging from 1 (inadequate) to 3 (least acceptable), 5 (qualified), 7 (good), and 9 (excellent). Each item includes three sub-items of material and space, opportunity and time, design and organization.

For the study by using the Activities Scale to measure the quality of play center activities, the Cronbach's coefficient of the whole scale is 0.89 . Meanwhile, the coefficients of the six items were all greater than 0.82 (between 0.82 and 0.95 ), and the total explanatory variation of the six dimensions was $84.52 \%$, indicating that the scale had good reliability and validity.

\subsection{Data Collection and Analysis}

Two raters from the research team entered each selected classroom to conduct classroom observation using CECERS. The raters received scoring skills training before using the CECERS scale. The training consisted of several days of intensive study of the instrument and field rating practice that included independenT-testing and group discussions. Each rater was required to achieve consistent results with the trainer, and the consistency reliability coefficient of raters reached 0.85 . Each observation of the classroom lasted about 6 hours (typically four hours in the morning and two hours in the afternoon).

Before the formal observation, raters were asked to draw a spatial layout of the entire classroom, indicating the locations and names of the group teaching areas and each activity area. Secondly, the weekly curriculum plan of the observed class was obtained to confirm the time and duration of play center activities in the daily schedule. During the observation, it is faithful to the definition of various indicators and related terms in the scale. The focus of observation is the process of activities and interaction. Different observation methods are adopted for different observation items. The sub-item "materials and space" observations were focused on the spatial layout of each play center and the number of materials in the classroom in the class gap time; "Opportunity and time" observations were conducted according to the weekly curriculum plan, the whole day observation and necessary interviews with teachers. "Organization and guidance" observations were focusd on the usage of materials and toys, and the behavior performance of children and teachers in the play.

Descriptive statistics were mainly used to analyze the overall quality and three dimensions quality of play center activities in China. Besides, the T-test was used to better show the differences in play center activities between different regions, funding sources, and levels of kindergartens.

\section{Results}

\subsection{Overall quality of play center activities}

The overall quality of play center activities is calculated as the average of each item score. On the scale of 1 (inadequate), 3 (minimal), 5 (qualified), 7 (good), 9 (excellent), the overall quality rating for the 48 K2 (4-5 years old) classrooms is slightly above minimal. The total average score is 4.28 , which is higher than the minimum level of 3 points, but lower than the qualified level of 5 points, indicating that the overall level of play center activities is not high. The overall quality of play center activities in some sample kindergartens is judged from inappropriate (1 point) to maximum good level ( 7 points).

According to the Central Limit Theorem, the sample size is greater than or equal to 30, and the sample mean tends to be normally distributed, which is suitable for statistical analysis (Wu \& $\mathrm{Tu}, 2006$ ). The Kolmogorov-Smirnov test results show that the sample data conform to the normal distribution $(p>0.05)$. The independent sample T-test results show that there are significant differences in the overall quality of play center activities between urban and rural, private and public, high and low level of kindergartens, which are manifested as follows: (1) The overall quality of play center activities in urban kindergartens is higher than that in towns and villages. (2) The overall quality of play center activities of first-class at provincial and municipal level is significantly higher than that of standardized and unrated kindergartens. (3) The overall quality of play center activities in public is significantly higher than that in private kindergartens (Table 3).

\subsection{Materials and Space Quality of Play Center Activities}

Materials and space of play center activities mainly involve the richness, safety and suitability of materials, space, and equipment for center activities. The total average scores of materials and space observed is less than 5 points, reaching between the minimum requirements and qualified level (Table 4). In addition to fine motor 
Table 3. Comparison of the overall quality of ECERS_Activities

\begin{tabular}{|c|c|c|c|c|c|c|}
\hline Variable & & $M$ & $S D$ & $t$ & Compare & \\
\hline \multirow[t]{2}{*}{ Location } & Urban & 3.64 & 1.18 & $5.27^{* *}$ & Urban $>$ Rural & \\
\hline & Rural & 5.56 & 1.22 & & & \\
\hline \multirow[t]{2}{*}{ Level } & $\begin{array}{l}\text { First-class at provincial } \\
\text { and municipal level }\end{array}$ & 4.87 & 1.59 & $2.68^{* *}$ & $\begin{array}{l}\text { First class }> \\
\text { and unrated }\end{array}$ & Standardized \\
\hline & Standardized and unrated & 3.78 & 1.22 & & & \\
\hline \multirow{2}{*}{$\begin{array}{l}\text { Funding } \\
\text { Source }\end{array}$} & Private & 3.97 & 1.37 & $-2.64^{* *}$ & Public $>$ Private & \\
\hline & Public & 5.21 & 1.52 & & & \\
\hline
\end{tabular}

activities, the lowest score of materials and space in each center is inappropriate for 1 point, indicating that materials and space in some kindergartens are not suitable for children's development requirements. The average score of materials and space in fine motor activities is the highest, reaching 5.67 points $(\operatorname{Min}=3$, Max $=9$ ) higher than the qualified level, which indicates that all kindergartens attach great importance to the development of fine motor for children, and sufficient materials are provided. Secondly, the score of materials and space in blocks, math and language area reach 5 points or nearly 5 points (the qualified level), which indicates that in these areas there are enough materials supplied for some 3 to 4 children to play at the same time. Unfortunately, the scores of materials and space in the role play and science area are only about 3 points (the minimal level), which indicates that the number of materials provided is minimal and cannot meet the needs of multiple children`s activities.

Table 4. Descriptive statistics of materials and space quality of play center activities

\begin{tabular}{lllll}
\hline Variable & $M$ & $S D$ & Min & Max \\
\hline MS-Total & 4.67 & 1.58 & 1.71 & 7.86 \\
MS-Role Play & 3.44 & 2.21 & 1.00 & 9.00 \\
MS-Blocks & 5.42 & 2.37 & 1.00 & 9.00 \\
MS-Fine Motor & 5.67 & 1.95 & 3.00 & 9.00 \\
MS-Language 1 & 4.54 & 2.05 & 1.00 & 9.00 \\
MS-Language 2 & 4.71 & 2.01 & 1.00 & 9.00 \\
MS-Math & 5.02 & 1.60 & 1.00 & 9.00 \\
MS-Nature/Science & 3.92 & 2.10 & 1.00 & 7.00 \\
\hline
\end{tabular}

The independent sample T-test results show that there are significant differences in the materials and space quality of play center activities between urban and rural, private and public, high and low level of kindergartens (Table 5). (1) The materials and space quality of play center activities in urban kindergartens is higher than that in towns and villages. (2) The materials and space quality of play center activities in public is significantly higher than that in private kindergartens. (3) The materials and space quality of play center activities of first-class at provincial and municipal level is significantly higher than that of standardized and unrated kindergartens.

\subsection{Opportunity and Time Quality of Play Center Activities}

Opportunity and time of play center activities mainly examine how many opportunities (times) and time (length) of a child are free to choose and use the area materials and space. The total average scores of opportunities and time observed is less than 5 points, reaching between the minimum requirements and quality level (Table 6). Except for fine motor activities, the scores of opportunity and time in other areas get the lowest 1 point, indicating that the opportunities and time of some kindergartens are not suitable for the requirements of children`s development. The average scores of opportunity and time in blocks, fine motor, and math area are 
Table 5. Comparison of materials and space quality of play center activities

\begin{tabular}{|c|c|c|c|c|c|}
\hline Dimension & Variable & $M$ & $S D$ & $t$ & Compare \\
\hline \multirow{6}{*}{$\begin{array}{l}\text { Material } \\
\text { Space }\end{array}$} & Rural & 4.0045 & 1.28571 & \multirow[t]{2}{*}{$-5.198^{* * *}$} & \multirow[t]{2}{*}{ Urban $>$ Rural } \\
\hline & Urban & 6.0089 & 1.24591 & & \\
\hline & Private & 4.3849 & 1.47271 & \multirow[t]{2}{*}{$-2.280^{*}$} & \multirow[t]{2}{*}{ Public $>$ Private } \\
\hline & Public & 5.5357 & 1.63918 & & \\
\hline & Standardized and unrated & 4.0989 & 1.27888 & \multirow[t]{2}{*}{$-2.950^{*}$} & \multirow{2}{*}{$\begin{array}{l}\text { First class }>\text { Standardized } \\
\text { and unrated }\end{array}$} \\
\hline & $\begin{array}{l}\text { First-class at provincial } \\
\text { and municipal level }\end{array}$ & 5.3506 & 1.65940 & & \\
\hline
\end{tabular}

higher than 5 points (the qualified level), indicating that children have a specific chance of 1-2 times per week (at least 30 minutes each time) to play. The scores of opportunity and time in the role play and science area is just above 3 points (the minimal level), indicating that children only have unique or scattered opportunities to play once a week.

Table 6. Descriptive statistics of opportunity and time quality of play center activities

\begin{tabular}{lllll}
\hline Variable & $M$ & SD & Min & Max \\
\hline Total-OT & 4.61 & 1.40 & 1.50 & 7.00 \\
OT-Role Play & 3.40 & 2.43 & 1.00 & 9.00 \\
OT-Blocks & 5.19 & 2.39 & 1.00 & 9.00 \\
OT-Fine Motor & 5.54 & 1.91 & 2.00 & 9.00 \\
OT-Language & 4.81 & 1.82 & 1.00 & 9.00 \\
OT-Math & 5.21 & 1.81 & 1.00 & 9.00 \\
OT-Nature/Science & 3.52 & 1.92 & 1.00 & 9.00 \\
\hline
\end{tabular}

The independent sample T-test results show that there are significant differences in the opportunity and time quality of play center activities between urban and rural, private and public kindergartens (Table 7). (1) The opportunity and time quality of play center activities in urban kindergartens is higher than that in towns and villages. (2) The opportunity and time quality of play center activities in public is significantly higher than that in private kindergartens. (3) There was no significant difference between high (first-class at provincial and municipal level) and low (standardized and unrated) level of kindergartens on the opportunity and time quality of play center activities.

Table 7. Comparison of opportunity and time quality of play center activities

\begin{tabular}{|c|c|c|c|c|c|}
\hline Dimension & Variable & $M$ & $S D$ & $t$ & Compare \\
\hline \multirow{6}{*}{$\begin{array}{l}\text { Opportunity } \\
\text { and Time }\end{array}$} & Rural & 4.1094 & 1.25053 & \multirow[t]{2}{*}{$-4.217^{* * *}$} & \multirow[t]{2}{*}{ Urban $>$ Rural } \\
\hline & Urban & 5.6187 & 1.12599 & & \\
\hline & Private & 4.3583 & 1.38574 & \multirow[t]{2}{*}{$-2.472^{*}$} & \multirow[t]{4}{*}{ Public $>$ Private } \\
\hline & Public & 5.3750 & 1.17878 & & \\
\hline & Standardized and unrated & 4.2782 & 1.30874 & \multirow[t]{2}{*}{-1.847} & \\
\hline & $\begin{array}{l}\text { First-class at provincial } \\
\text { and municipal level }\end{array}$ & 5.0076 & 1.42491 & & \\
\hline
\end{tabular}




\subsection{Design and organization Quality of Play Center Activities}

Design and organization of play center activities focus on the development suitability of the design and content of the corner activities, the teachers' supervision and guidance to the children, and the interaction with children. The total average scores of design and organization observed is less than 5 points, reaching between the minimum requirements and quality level (Table 8). Except for the nature/science area, the lowest score of design and organization in each area all showed an inappropriate situation (1 point), indicating that the organization and guidance of some kindergartens were not suitable for the requirements of children's development. The average scores of design and organization in blocks, fine motor, and math area received more than 5 points (the qualified level), indicating that the materials provided by the kindergartens for these areas are suitable for children's age and ability, and the guidance of teachers is basically appropriate. However, it fails to consider the correlation between activities and curriculum themes and lacks individualized interaction and guidance with children. In contrast, the scores of design and organization in role play are only higher than 3 points (the minimal level), which indicates that there is no obvious improper instruction.

Table 8. Descriptive statistics of design and organization quality of play center activities

\begin{tabular}{lllll}
\hline Variable & $M$ & $S D$ & Min & Max \\
\hline Total-DO & 4.67 & 1.41 & 1.00 & 7.50 \\
DO-Role Play & 3.72 & 2.26 & 1.00 & 9.00 \\
DO-Blocks & 5.02 & 1.92 & 1.00 & 9.00 \\
DO-Fine Motor & 5.24 & 2.02 & 1.00 & 9.00 \\
DO-Language & 4.93 & 1.86 & 1.00 & 9.00 \\
DO-Math & 5.09 & 1.67 & 1.00 & 9.00 \\
DO-Nature/Science & 4.09 & 1.44 & 2.00 & 7.00 \\
\hline
\end{tabular}

The independent sample T-test results show that there are significant differences in the design and organization quality of play center activities between urban and rural, private and public, high and low level of kindergartens (Table 9). (1) The design and organization quality of play center activities in urban kindergartens is higher than that in towns and villages. (2) The design and organization quality of play center activities in public is significantly higher than that in private kindergartens. (3) The design and organization quality of play center activities of first class at provincial and municipal level kindergartens is significantly higher than that of standardized and unrated kindergartens.

Table 9. Comparison of design and organization quality of play center activities

\begin{tabular}{|c|c|c|c|c|c|}
\hline Dimension & Variable & $M$ & $S D$ & $t$ & Compare \\
\hline \multirow{6}{*}{$\begin{array}{l}\text { Design and } \\
\text { Organization }\end{array}$} & Rural & 4.0292 & 1.11820 & \multirow[t]{2}{*}{$-5.870^{* * *}$} & \multirow[t]{2}{*}{ Urban $>$ Rural } \\
\hline & Urban & 5.9438 & 1.03778 & & \\
\hline & Private & 4.3611 & 1.32280 & \multirow[t]{2}{*}{$-2.777^{*}$} & \multirow[t]{2}{*}{ Public $>$ Private } \\
\hline & Public & 5.5861 & 1.32348 & & \\
\hline & Standardized and unrated & 4.2564 & 1.07983 & \multirow[t]{2}{*}{$-2.285^{*}$} & \multirow{2}{*}{$\begin{array}{l}\text { First class }>\text { Standardized and } \\
\text { unrated }\end{array}$} \\
\hline & $\begin{array}{l}\text { First class at provincial } \\
\text { and municipal level }\end{array}$ & 5.1530 & 1.62255 & & \\
\hline
\end{tabular}

\section{Discussion}

The findings from this study lead to four main conclusions.

First, the results showed that the overall quality of play center activities in China is between the minimum and qualified level, and there are significant differences between urban and rural, private and public, high and low 
level of kindergartens. The results are consistent with the existing descriptions of play center activities in China (Chen \& Li, 2014; Luo, 2014; Hu et al., 2015). The findings provide empirical support for teachers' beliefs about play center activities in Chinese cultural context (Hua, 2008; Zhu, 2007). In China, A balanced approach to teacher-directed whole-group teaching and child-initiated play was supported as the proper way to early childhood education (Hu et al., 2014). As a matter of fact, studies have shown that the teachers are more inclined to teacher-led play teaching approach rather than child-led free play although these teachers might highly agree with the value of play center activities (Li et al., 2014; Hu et al., 2015). As the result of observation, compared with whole-group teaching of 2-3 hours, the time of play center activities is only $0.5-1$ hour in the schedule of kindergarten, and even some of the kindergartens do not arrange any play center activities in the schedule. Although large class sizes $(M=36)$ and high student-teacher ratios $(M=16.21: 1)$ in Chinese classroom are contributed to whole-group teaching rather than play center activities in kindergartens (Zhu, 2007; Wu, Young, \& Cai, 2012), it also shows that the play center activities in practice are not ideal as approval in concept. Different from the studies in other countries, play center activities in China show obvious differences between urban and rural, private and public, high and low level of kindergarten. These significant differences are mainly due to the urban-rural education quality disparity in China (Hu et al., 2014). Public institutions are more likely to be concentrated in urban areas, and they usually get a higher level of quality due to more funding resources from government and other public sectors, while most private and rural programs have a much lower level of quality. The results remind policymakers to pay more attention to the urban-rural disparity in early childhood education, and take continuous measures to reduce the urban-rural differences so that young children can have access to a balanced education.

Second, materials and space quality of play center activities is between the minimum requirements and qualified level, and shows significant differences between urban and rural, private and public, high and low level of kindergartens. Studies have revealed that the provision and preparation of materials also affect the activities and performance of young children. The richer the materials provided in the area, the more positive behaviors and less negative behaviors young children will have (Huang, Li, \& Zhong, 2018). Similar to existing research findings, play center activities in Chinese kindergartens also lack sufficient space and materials (Xu \& Zhao, 2014; Huang, 2014; Chen \& Li, 2014). The large size of classes in China leads to insufficient space for the play centers. Meanwhile, the lack of investment and experience makes it difficult for teachers to combine children`s interests with material characteristics (Yang, 2011; Chen \& Li, 2014). Some typical problems of improper space and materials have been presented in the existing research, including (1) The environment and setting of play center is relatively fixed; (2) The placement of materials is more casual; (3) The types and quantities of materials are not rich enough to allow a small group of children to participate (Han, 2013; Huang, 2014; Xu \& Zhao, 2014). Therefore, it is suggested that kindergartens and teachers should design and arrange activity space properly. The creation of environments should consider the individual development level and interest of children to ensure that the environment is meaningful to each child's development through child observation, conversation, discussion, and other evaluation methods. Materials should be rotated regularly to maintain children's interest so as to stimulate children's curiosity of play constantly With providing multiple meaningful spaces and a variety of materials for children to practice specific skills, children are able to exercise self-regulation, self-control, initiative, and enthusiasm, so that their learning is relatively free from intrusion and direction of teachers.

Third, opportunity and time quality of play center activities is below the quality level and shows significant differences between urban and rural, private and public kindergartens. This is consistent with the research results of decreased time and opportunities for children for free play in other studies. Compared with previous generations, children were more involved in studies and learning activities, and the time and opportunities for free play were significantly reduced, which is the same in China (Howes et al., 1992; Isenberg \& Quisenberry, 2002; Ma, 2014). Moreover, compared with free play at least one-third of the prekindergarten hours in the U.S.A., there are not enough opportunities and time for free play in the daily schedule in Chinese kindergartens, which has shown by past research (Yang, 2011; Chen \& Li, 2014; Wu \& Shao, 2016). According to the survey results by Wu and Shao (2016), some play center activities are only arranged for half an hour in entry and departure time, while some are crowded out by other activities such as transitions and waiting sessions. Most teachers do not allow children to choose their activities independently for the convenience of management. Under the high control of teachers, the lack of sufficient time in play center is a common problem in play center activities in China. Therefore, for most kindergartens, it is necessary to respect the right to play and significantly increase the opportunities and time of play in kindergarten. Considering the tendency of group teaching in Chinese kindergartens, professionals recommend that young children should have at least one hour a day, preferably two to three hours of free play supported by adequate materials (Liu, 2004; Huang, 2014; Hu et al., 
2015).

Forth, design and organization quality of play center activities is between the minimum requirements and qualified level and shows significant differences between urban and rural, private and public, high and low level of kindergartens. It is observed that kindergarten teachers interact minimally with children during play center activities, while the organization and instruction of teachers has proven to be a crucial reason for a high level of play in practice (Nikolakaki, 2012).,However, there is a general lack of guidance and organization from teachers in play center activities (Wu \& Shao, 2016; Gu, 2016), or teachers lack adequate guidance strategies (Henniger,1993; Duncan \& Tarulli, 2003; Johnson et al., 2005; Han, 2013; Hu et al., 2015). Hirsh-pasek, et al. (2009) pointed out that child-led free play often requires the teacher to nimbly and skillfully engaged with full experience of instruction, but Chinese kindergarten teachers seem to lack appropriate guidance because they either do not realize it or do not know how to use embedded learning opportunities. Therefore, teachers should accurately understand the importance and value of play first, which should not only remain in the concept but should also be implemented in educational practice. Then teachers need to be able to support children's learning in a variety of ways, including observing, building scaffolding, supporting peer interaction, helping them follow the rules, stay safe, and document their learning. A variety of tips can also be used to help children with available materials. Teachers can use language prompts (oral talk in the play scene), model prompts (demonstrating to the child how to interact with a toy or other child), or action prompts (guiding the child to complete the behavior). In general, teachers need to gain practical skills for implementing child-centered developmentally appropriate play (Hu et al., 2014). Professional development work should be provided for kindergarten teachers to improve the quality of child-centered play and learning.

This study has its limitations. First, it took place in an advanced province in China, and its findings cannot be extended to other regions in China, especially in areas with low levels of socioeconomic development. Second, previous studies have revealed that the ECERS-R scale focuses more on the structural quality of education (Sylva et al., 2006; Hu et al., 2015). In order to further understand the process of play center activities, other well-established quality measures can be used, such as Classroom Assessment Scoring System (CLASS; Pianta, La Paro, \& Hamre, 2008) to obtain more validity evidence of play center activities. Finally, how do play center activities predict children's development in Chinese social and cultural contexts? The relationship between the quality of play center activities and children`s development needs to be further explored.

\section{Acknowledgments}

The following grants support the manuscript: Research on Digital Multi-model Text Reading of Children from National Education Science Planning Project -Key Issues of the Ministry of Education of China (DHA170339); A Longitudinal Study on the Effects of Preschool Program Quality on Children's Learning and Development Outcomes from University of Macau Multi-Year Research Grant (MYRG2015-00156-FED; MYRG2015-00156-FED).

\section{References}

Barnett, W. S. (2003). Better Teachers, Better Preschools: Student Achievement Linked to Teacher Qualifications. NIEER Preschool Policy Matters, 2.

Catron, C. E., \& Allen, J. (2007). Early childhood curriculum: A creative play model. Prentice Hall.

Chen, J., \& Li, K. (2014). Research on the correlation between activity quality and the development of children. Early Childhood Education, 55-56(1-2), 7-11.

Chudacoff, H. P. (2007). Children at play: An American history. New York University Press. https://doi.org/10.1086/ahr.113.3.815a

Copple, C., \& Bredekamp, S. (2009). Developmentally appropriate practice in early childhood programs serving children from birth through age 8. National Association for the Education of Young Children. 1313 L Street NW Suite 500, Washington, DC 22205-4101.

Cryer, D., Harms, T., \& Riley, C. (2003). All about the ECERS-R. Lewisville, NC: Kaplan.

Davidson, J. I. F. (1998). Language and play. Play from birth to twelve and beyond: Contexts, perspectives and meanings, 970, 175-185.

Duncan, R. M., \& Tarulli, D. (2003). Play as the leading activity of the preschool period: Insights from Vygotsky, Leont'ev, and Bakhtin. Early Education \& Development, 14(3), 271-292. https://doi.org/10.1207/ s15566935eed1403_2

Elias, C. L., \& Berk, L. E. (2002). Self-regulation in young children: Is there a role for sociodramatic play? Early 
Childhood Research Quarterly, 17(2), 216-238. https://doi.org/10.1016/s0885-2006(02)00146-1

Epstein, A. S. (2014). The intentional teacher: Choosing the best strategies for young Children's learning (Rev. ed.). Washington, DC: National Association for the Education of Young Children.

Fisher, K., Hirsh-Pasek, K., Golinkoff, R. M., Singer, D. G., \& Berk, L. (2011). Playing around in school: Implications for learning and educational policy. https://doi.org/10.1093/oxfordhb/ 9780195393002.013.0025

Gol-Guven, M. (2009). Evaluation of the quality of early childhood classrooms in Turkey. Early Child Development and Care, 179(4), 437-451. https://doi.org/10.1080/03004430701217639

Good, T. L., \& Brophy, J. E. (1974). Changing teacher and student behavior: An empirical investigation. Journal of Educational Psychology, 66(3), 390. https://doi.org/10.1037/h0036499

$\mathrm{Gu}, \mathrm{L}$. (2016). Kindergarten play center activities: problems and development trends. Educational Exploration, 5, 54-57.

Han, L. (2013). Strategies for kindergartens to develop play center activities. Early Childhood Education Research, 9, 70-72

Hirsh-Pasek, K., Golinkoff, R. M., Berk, L. E., \& Singer, D. G. (2009). A mandate for playful learning in preschool: Presenting the evidence. New York: Oxford University Press. https://doi.org/10.1093/ acprof:oso/9780195382716.001.0001

Holt, J. (2010). "Normal” versus "Deviant" Play in Children`s Literature: An Historical Overview. The Lion and the Unicorn, 34(1), 34-56. https://doi.org/10.1353/uni.0.0486

Hu, B. Y., Dieker, L., Yang, Y., \& Yang, N. (2016). The quality of classroom experiences in Chinese kindergarten classrooms across settings and learning activities: Implications for teacher preparation. Teaching and Teacher Education, 57, 39-50. https://doi.org/10.1016/j.tate.2016.03.001

Hu, B. Y., Fan, X., Sao Leng Ieong, S., \& Li, K. (2015). Why is group teaching so important to Chinese Children`s development? Australasian Journal of Early Childhood, 40(1), 4-12. https://doi.org/10.1177/ 183693911504000102

Hu, B. Y., Fan, X., Wu, Z., LoCasale-Crouch, J., Yang, N., \& Zhang, J. (2017). Teacher-child interactions and children`s cognitive and social skills in Chinese preschool classrooms. Children and Youth Services Review, 79, 78-86. https://doi.org/10.1016/j.childyouth.2017.05.028

Hu, B. Y., Zhou, Y., Li, K., \& Killingsworth, R. S. (2014). Examining program quality disparities between urban and rural kindergartens in China: Evidence from Zhejiang. Journal of Research in Childhood Education, 28(4), 461-483. https://doi.org/10.1080/02568543.2014.944720

Hua, A. (2008). What to pursuit in kindergarten`s group teaching: effectiveness, or meaningfulness. Early Childhood Education, 10, 6-8.

Huang, C., Li, L., \& Zhong, B. (2018). Should kindergarten class size be increased under the "universal two-child policy"? -- a meta-analysis of the relationship between structural quality and process quality in kindergarten classes in China. Chinese Journal of Education, 9, 81-86.

Huang, J. (2014). Sources and challenges of play center activities in kindergartens. Early Childhood Education Research, 10, 31-35.

Johnson, J. E., Christie, J. F., \& Wardle, F. (2005). Play, development, and early education. Pearson/Allyn and Bacon.

Li, K., \& Hu, B. (2012). Chinese Early Childhood Environment Rating Scale. Unpublished instrument.

Li, K., Hu, B., Pan, Y., Qin, J., \& Fan, X. (2014). Chinese Early Childhood Program Rating Scale: A validity study. Early Childhood Research Quarterly, 29(3), 268-282. https://doi.org/10.1016/j.ecresq.2014.02.007

Liu, Y. (2004). General theory on children 's play. Beijing: Beijing Normal University Publisher.

Luo, Y. Q. (2014). Evaluation of the quality of play activities in model kindergartens. Hunan Normal University.

Ma, L. (2014). Play in the daily life of kindergartens between China and Norway, East China Normal University.

Mwaura, P. A., Sylva, K., \& Malmberg, L. E. (2008). Evaluating the Madrasa preschool program in East Africa: a quasi-experimental study. International Journal of Early Years Education, 16(3), 237-255. https://doi.org/10.1080/09669760802357121 
Nikolakaki, M. (2012). Building a Society of Solidarity Through Critical Pedagogy: Group Teaching as a Social and Democratic Tool. Journal for Critical Education Policy Studies, 10(2).

Panksepp, J. (2007). Can PLAY diminish ADHD and facilitate the construction of the social brain? Journal of the Canadian Academy of Child and Adolescent Psychiatry, 16(2), 57.

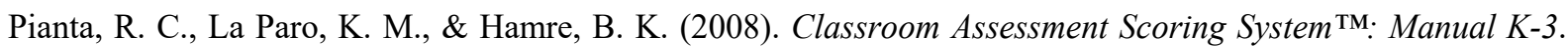
Paul H Brookes Publishing.

Schweinhart, L. J., \& Weikart, D. P. (1988). Education for young children living in poverty: Child-initiated learning or teacher-directed instruction? The Elementary School Journal, 89(2), 213-225. https://doi.org/10.1086/461574

Spodek, B., \& Saracho, O. N. (2014). Handbook of research on the education of young children. Routledge. https://doi.org/10.4324/9781315045511

Sylva, K., Siraj-Blatchford, I., Taggart, B., Sammons, P., Melhuish, E., Elliot, K., \& Totsika, V. (2006). Capturing quality in early childhood through environmental rating scales. Early Childhood Research Quarterly, 21(1), 76-92. https://doi.org/10.1016/j.ecresq.2006.01.003

Wu, K. B., Young, M. E., \& Cai, J. (2012). Early child development in China: Breaking the cycle of poverty and improving future competitiveness. The World Bank. https://doi.org/10.1596/978-0-8213-9564-6

Wu, M., \& Tu, J. (2006). SPSS and statistical application analysis. Wannan Books Press.

Xu, Y., \& Zhao, R. (2014). play center activities guided by Guidance of Learning and Development of Children aged 3-6 years. Journal of Neimenggu Normal University (education science edition), 6, 73-75.

Yang, L., \& Deng, X. (2012). Research on the effectiveness of teacher guidance in kindergarten play center activities_taking some kindergartens in Hunan province as examples, Teacher Education Research, 24(2), 33-37.

Yang, X. W. (2011). Cultivation of children`s autonomy in play center activities. China External Education, 13, 149.

Zhu, J. X. (2007). To teach or not: On the value of group teaching in Chinese kindergartens. Early Childhood Education, 9, 4-6.

Zigler, E. F., Singer, D. G., \& Bishop, S. J. (2004). Children `s play: The roots of reading. Washington, DC: Zero to Three.

\section{Copyrights}

Copyright for this article is retained by the author(s), with first publication rights granted to the journal.

This is an open-access article distributed under the terms and conditions of the Creative Commons Attribution license (http://creativecommons.org/licenses/by/4.0/). 